\title{
LATEST ADVANCEMENTS IN MANAGEMENT AND TREATMENT OF EPIDEMIOLOGY OF IMMUNODEFICIENCY COMPLEXITIES
}

\author{
Monirul Islam
}

Assistant Professor of Marketing Management. Xavier Business School (XBS), St Xavier's University, Kolkata, West Bengal. *Corresponding Author's Email: moni05081985@gmail.com

\begin{abstract}
The human immunodeficiency virus is the cause of AIDS, which attacks the body's immune system. This retrovirus transmits through blood, semen, and breast milk that infects immune cells and destroying their functions. In 1995, Food and Drug Administration approved highly active antiretroviral therapy treatment, which has accelerated the abrupt drop of between $60 \%$ and $80 \%$ in rates of AIDS-associated deaths in several countries globally. After two decades, for the first time in 2017, more than half of the world's populations living with HIV are receiving antiretroviral therapy. The antiretroviral therapy is most common and suitable process. However, it creates pill burden, toxicity. Therefore, recent developments like nanotechnology shock and kill process, mRNA technology, Gene editing helps to reduce pill burden. The paper throws light on the mean infection rate, recovery rate, and active cases. For that, world's death rate is under control. Living with HIV rates are increasing. Mortality rate is decreasing. The researcher tries to collate the latest advancements in Management and Treatment of Epidemiology immunodeficiency complexities, in this case HIV disease. The major thrust is on the effective management \& treatment.
\end{abstract}

Keywords: Epidemiology Management, immunodeficiency, antiretroviral therapy, Nanotechnology, disease control.

\section{INTRODUCTION}

AIDS is Acquired immunodeficiency syndrome which chronic and life-threatening disease that usually develops in people with HIV. By the early 1990s, AIDS was the main cause of death among Americans ages 25 to 44 . Past few decades, medical sciences changed a lot. From antiretroviral therapy (ART) to enter stage of immunotherapy is not that easy. New era of gene therapy, immunotherapy and nanotechnology are latest approaches aimed at long-term remission of HIV. In the early 1960, the cause of AIDS is HIV found in the United States and the epidemic of infections had peaked around the mid-1980s. After two decades, for the first time in 2017, more than half of the world's populations living with HIV are receiving ART.
However, when the world is entered the fourth decade of the HIV epidemic. New drugs have developed with the help of using modern technology that addresses current challenges with antiretroviral therapy (ART), such as pill burden, toxicity, and drug resistance.

Nanotechnology also is helping a lot nowadays to deliver drugs into the human body and with help of modern techniques; new agents are delivering to suppress viral replication. A combination of Integrase inhibitors and chemokine receptor blockers with NRTIs, NNRTIs, and PIs, are developing new highly active ART which able to tackle all aspects of the HIV life cycle with minimal toxicity. Pharmaceutical companies are able to formulate these powerful new drugs into fixeddose combinations with exciting

CThe Author(s) 2021. Published by Iquz Galaxy Publisher, India.. This is an Open Access article distributed under the terms of the Creative Commons Attribution CC BY license (http://creativecommons.org/licenses/by/4.0/), which permits unrestricted reuse, distribution, and reproduction in any medium, provided the original work is properly cited. 
new strategies for reducing pill burden. It ensures limiting the emergence of drug resistance. These developments in the current scenario are helping to access treatment in low- and middle-income countries. This time is not far when the vast majority of patients will receive newer agents and new HIV treatments and we would live in an AIDSfree generation.

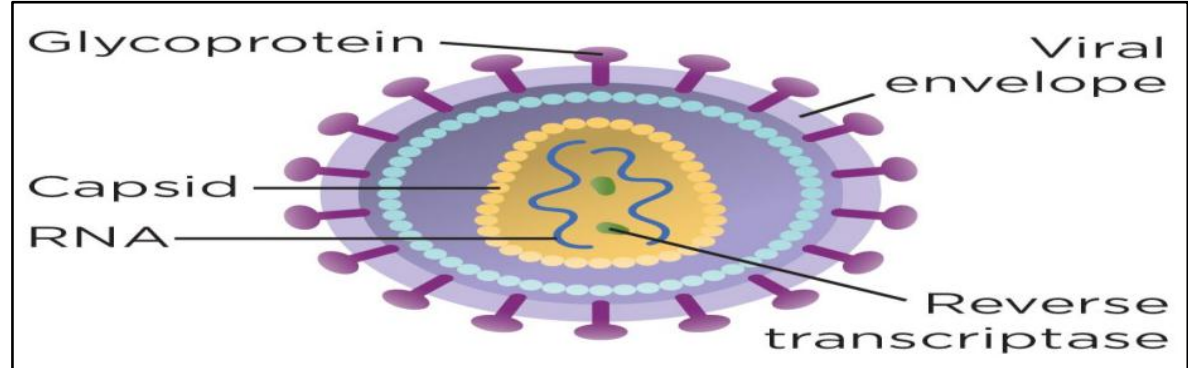

Figure 1: Genetic structure of AIDS virus (Source: Nursing Times [online]; 116: 7, 39-41).

\section{SIGNIFICANCE OF STUDY}

In this modern era increase in effective treatments for HIV, people with HIV are living longer, healthier, and more productive lives. Deaths from AIDS have potentially declined in the United States since the 1990s. As the number of people living with HIV rises, the author hope it will be more important to increase awareness and management of HIV prevention and health care programs. The number of people living with HIV increases in the past two decades. HIV is a life-threatening disease so more people should become aware of HIV status, prevention strategies of this. In addition, change of the mind-set towards HIV-infected people is becoming more important. People's perception in the USA about the seriousness of HIV has declined in recent years. The study signifies to new inventions that are helping to prevent and cure HIV, like:

- Antiretroviral therapy (ART)

- HIV Management \& Prevention Services

- Mental health check-up

- Other sexually transmitted infections screening and treatment

There are also new developments with modern technology innovated which will be discussed here in a detailed manner.

\section{OBJECTIVES OF STUDY}

i. To interpret statistics data regarding latest developments in HIV/AIDS treatment in world

ii. To gain the detailed knowledge about recent methods and management in HIV/AIDS treatment in world. iii. To assess the epidemiology regarding current developments in HIV/AIDS treatment in world

\section{LIMITATION}

- There were some challenges to collect data, as if data are not fully available.

- Recent developments and treatments are being observed in trial period.

- Trials are only conducted among individuals who are enrolled for the trial.

\section{METHODOLOGY}

A descriptive and exploratory research design is used for this study. The statistical data collated is further analysed using SPSS for descriptive statistics. Secondary data were collected and compiled from various journals, database sites like WHO, Nature, Science Direct, Web of Science, Biological Abstracts (part of Web of Science), Medline, Project Muse, PubMed etc has been referred.

\section{RESULTS}

The results can be depicted from below mentioned graphs and data. It is projecting that after introduction of HAART, world's death rates declined on a huge basis. However, a mean average or mean infections is desired. Therefore, by running SPSS, the mean, maximum and minimum with Standard deviation of death cases in world are calculated. Similarly, the results of active number of living cases were calculated and interpreted. 
Table 1: Descriptive Statistics of active HIV case

\begin{tabular}{|c|c|c|c|c|c|}
\hline & N & Minimum & Maximum & Mean & $\begin{array}{c}\text { Std. } \\
\text { Deviation }\end{array}$ \\
\hline $\begin{array}{c}\text { No. Of } \\
\text { Cases }\end{array}$ & 6 & $8,73,625$ & $36,80,000$ & $25,48,937.50$ & $10,41,779.85$ \\
\hline $\begin{array}{c}\text { Valid N (list } \\
\text { wise) }\end{array}$ & 6 & & & & \\
\hline
\end{tabular}

Above descriptive statistics are described results about living with HIV cases. Mean or avg. cases are near about 2.5 million. So, on average 2.5 million people in world are living with HIV in every year. Below descriptive statistics is showing mean value of death rates in world. On average, HIV virus per year dies 12 lakhs people.

Table 2: Descriptive Statistics mortality HIV rates

\begin{tabular}{|c|c|c|c|c|c|}
\hline & N & Minimum & Maximum & Mean & Std. Deviation \\
\hline No. Of Cases & 6 & $3,48,600$ & $19,50,000$ & $12,42,736.50$ & $6,06,857.33$ \\
\hline $\begin{array}{c}\text { Valid N (list } \\
\text { wise) }\end{array}$ & 6 & & & & \\
\hline
\end{tabular}

Mean of newly infected patients are slightly less than living with HIV. Mean of death rates is lowest than other two. World should more careful about death rates. Mostly South Africa, Ghana, and some parts of India need to more conscious about protected sex.

Table 3: Descriptive Statistics of newly infected patients

\begin{tabular}{|c|c|c|c|c|c|}
\hline & N & Minimum & Maximum & Mean & Std. Deviation \\
\hline $\begin{array}{c}\text { No. Of } \\
\text { Cases }\end{array}$ & 6 & 2.0 & 3.2 & 2.465 & 4,999 \\
\hline $\begin{array}{c}\text { Valid N (list } \\
\text { wise) }\end{array}$ & 6 & & & & \\
\hline
\end{tabular}

Value of Std. deviations help to predict dispersion. Variation in between two year's data or among data can observe by descriptive statistics. 


\section{FINDINGS AND ANALYSIS}

\section{Methods/Treatments for HIV/AIDS}

i) Antiretroviral therapy (ART): There is no complete cure for HIV yet but people can control by ART, which is general treatment. It is an effective treatment, which reduces amount of virus in the blood to an undetectable level. A combination of medicines needs to take every day for reducing virus level, which often creating such as pill burden, toxicity. However, from 1995, doctors are recommended ART for everyone who has HIV and still it is most approachable treatment for many countries. This method cannot able to cure HIV. The key goals of ART are:

a) ART helps to reduces amount of HIV in body. b) Reduces HIV transmission from one to another

c) Prevents from advance or next level of AIDS

d) Protects and develops immune system.

Procedure of ART: HIV attacks and destroys CD4 immune cells, which protect us from infections. Loss of CD4 cells makes problem to resist from infection and body feel weaker. Continuous fever and other disease are primary stage of HIV and it tends to extend up to HIV-related cancers. ART helps to control multiplying HIV, which is called viral load. Less no of HIV in the body helps immune system to recover and produce more CD4 cells. The chances of HIV in body are low and the immune system is strong enough to fight against infections and certain HIV-related cancers. Main aim of HIV treatment is to reduce viral load to an undetectable level. The outline of whole steps, a person with HIV takes from initial diagnosis through successful treatment through ART:

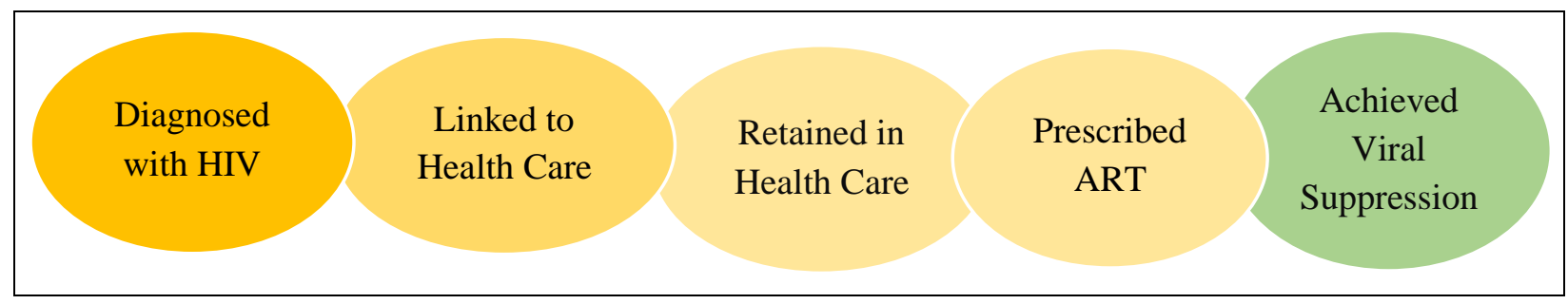

Figure 2: Steps of ART (Source: Author compilation).

HIV medicines comprised with seven drug classes according to how they fight HIV. However, now only one pill is solution for HIV.

ii) Abivax Drug mechanism to Stop HIV Replication:

One of the most advanced HIV cures technique by which inhibits the virus replication ability. This approach used in herpes infections treatment. It applied to control the spread of the infection. The Abivax initially released in market with clinical trial, found to possess the potential to cure HIV. The objective is to target the conglomerate of HIV that 'hide' undetected within cells. The major functionalities to targets the reservoir of HIV that hides in red blood cells remains undetected in the intestinal gut.

ABX464 drug is found effective in inhibiting HIV replication by splicing of viral mRNA and producing peptide antigens, which induces immune response. Without ABX464, HIV virus prevents mRNA splicing and helping to replicate new HIV.

\section{iii) Shock and Kill Process:}

The shock and kill approach is a two-step method. The drugs called latency-reversing agents in first stage are used to reactivate the latent HIV hiding in body immune cells (also known as the "shock"). Secondly, the reactivated cells can then be targeted and killed by the body's immune system or antiHIV drugs.

It is encouraging, but shock and kill procedure hasn't quite worked yet. It is under clinical trials. It is not yet proven potential in human bodies. It is not completely successful to control HIV.

Hurdles: - Risky, chances of reinfection, may lead neurocognitive disorders

iv) Immunotherapy to reduce HIV:

HIV is life threatening which attacks immune system and makes people unprotected against infections. Immunotherapy helps to supercharge immune cells for fight against virus and infections. Bill Gates had strongly supported this HIV immunotherapy and invested in immunocore. It also works in human tissue samples. However, this 
is a trial process and needs to check whether it is working in people living with HIV. Currently, the French InnaVirVax designs one of the recent advanced immunotherapy vaccine. This vaccine produces antibodies against the HIV protein $3 \mathrm{~S}$ and generates more T cells to destroy HIV viruses. After, Phase 2 a trial now this vaccine is combined with DNA-based vaccine and new vaccine is stronger than previous one.

The immunotherapy process comprises immunotherapeutic agents which are used to treat cancer and to destroy HIV virus by apoptosis.

\section{v) Treatment with Gene Editing:}

Estimated $1 \%$ people are developed immune system, which can control HIV virus and can produce $\mathrm{T}$ cells against AIDS. The gene, encoded with a protein CCR5 that is mutated. For this, HIV virus cannot able to bind to it for lack of some parts of gene. By help of gene editing, doctors can have mutated person's gene, after mutation, HIV cannot able to bind, and replication will stop. USbased Sangamo Therapeutics is trying to develop this approach. Immune cells from patients are extracted then uses zinc finger nucleases to edit their gene to make resistant.

In future by using gene-editing tool, CRISPR-Cas9 this gene editing will be easier. However, developing CRISPR babies are not ethically right and there might be certain consequences which against human policies. There might be risk to dying in younger age or infected by other diseases.

vi) Nanotechnology based HIV treatment: Nanotechnology can also play a major role in preventing AIDS and the Replication of HIV. There are many nanotechnologies-based drugs like liposomes, nanoparticles, etc. Liposomes are microscopic vesicles with phospholipids bilayers. The size of liposomes is near $25 \mathrm{~nm}$. After entering the human body, the liposome is detected as foreign bodies and engulfed by phagocytic cells. At that time, HIV also is present in the phagocytic cells. So, with help of liposome anti-HIV drugs can be added and targeting to HIV cells. Solid colloidal, Nanoparticles are capable to target specific sites. The size range is $10-1000 \mathrm{~nm}$. Most approved drug delivery agent. Nanoparticles are also well known for the improvement of formulation and drug efficacy.

Niosomes as an alternative to liposomes, nonionic surfactant vesicles. They are capable to target drugs and surfactant monomers. Polymeric micelles are composed of polymers and core-shell arrangements. The core composed of both hydrophobic and hydrophilic ends. It is surfactantbased micelles.

Dendrimers are composed of dendrons. It is divided into core, interior, and periphery. Empty space inside of dendrimers where drugs can be entrapped.

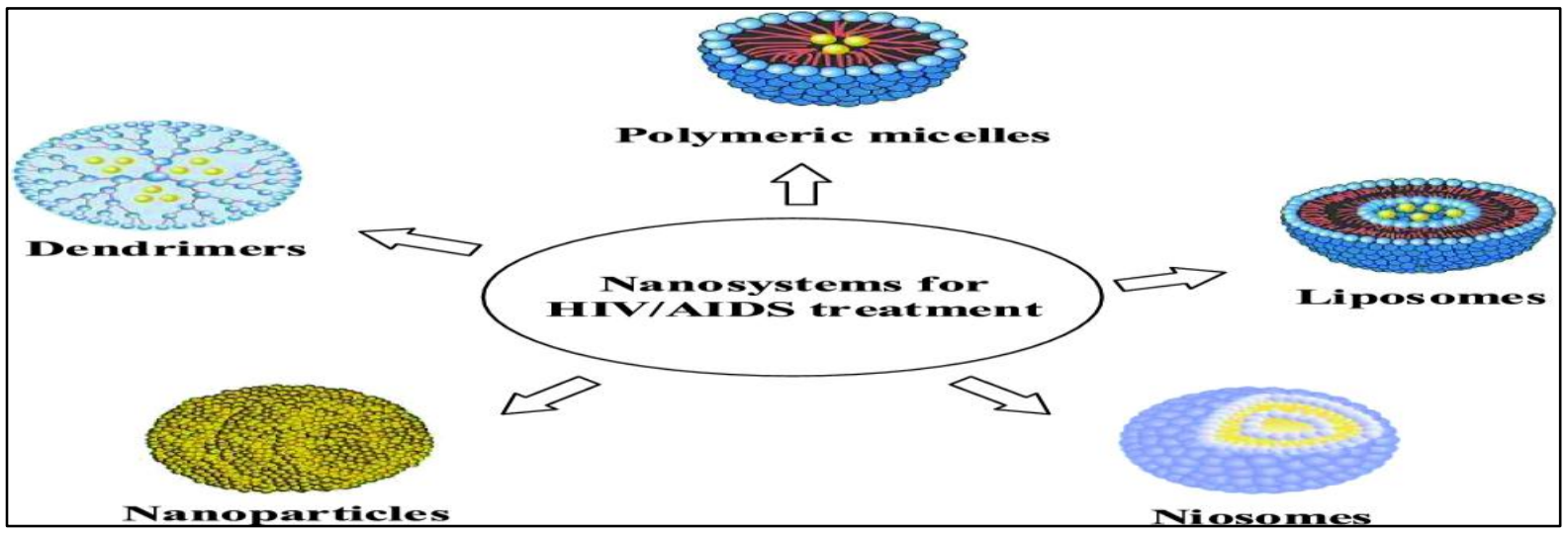

Figure 3: Nanotechnology based HIV treatment (Source: Naumović, M., Popović, N (2019)).

vii) mRNA-based Vaccine:_Recently in 2021, IAVI and Scripps Research will plan to collaborate with Moderna to develop an mRNA-based vaccine to prevent HIV infection. While Moderna is trying to develop a COVID vaccine, they developed this, which has an efficacy of $94 \%$ to kill
HIV viruses. Advanced mRNA technology, surely accelerates the pace of HIV vaccine development. The same technology used in COVID-19 jab, which is developed by Pfizer and BioNTech. 


\section{Epidemiology Management Strategy}

a. Prevention is better than cure. Awareness, information, persuasion and reminder strategy should be adopted- Local and National level

b. Early diagnosis through blood or saliva testing, pre marriage testing. Easy available tests include: Antigen/antibody tests, Antibody tests, Nucleic acid tests (NATs).

c. Tests to detect respective stage, disease progression and treatment

d. Tests for complications to other organs

e. Treatment of side effects to treatment

f. Treatment for age-related diseases

g. Lifestyle and home remedies h. Alternative medicine-supplements: boost immunity, decrease mortality and onset of disease

i. Mind-body practices

j. Coping and support: the fight is against the virus, not with the patients, not to stigmatise the patient \& family.

\section{DATA ANALYSIS AND INTERPRETATION}

This segment deals with data analysis and interpretation of HIV related data and gains knowledge of research developments. Data are collected from secondary sources and "Our world in data", Global statistics (hiv.gov). By analysis of these data, we will predict pace of development of treatment.

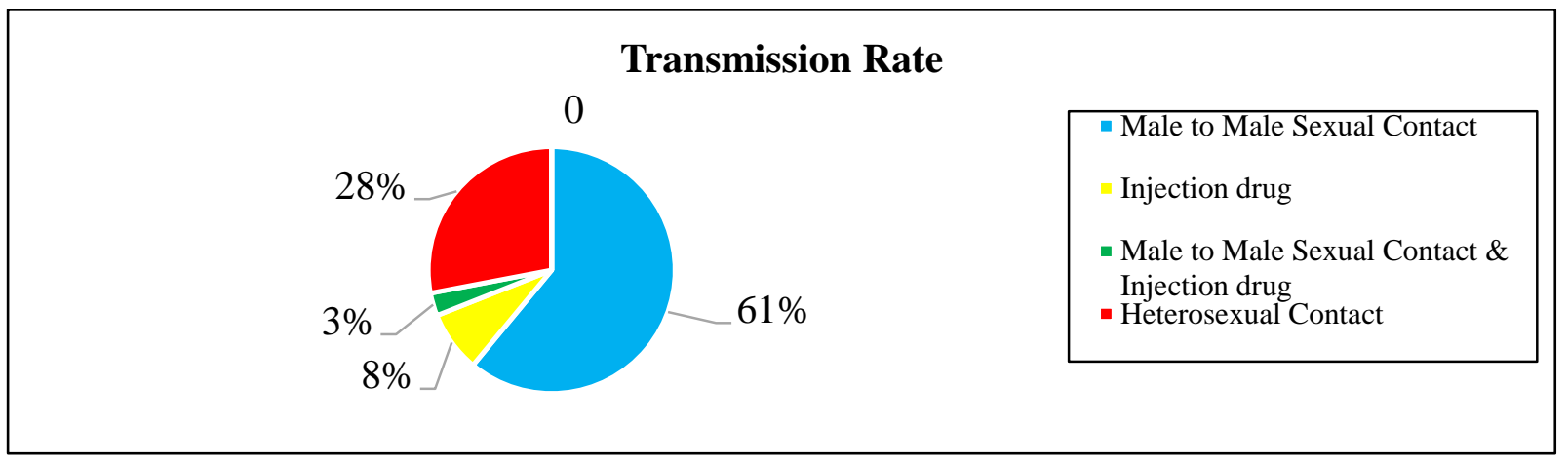

Figure 4: Risk of exposure to AIDS (Source: hiv.gov).

Transmission rate depends on mainly unprotected sex, injection drug. More than 61\% HIV infections came from Male to male sexual contact. Unprotected sex with HIV+ person carry transmission risk up to $2 \%$. In addition, heterosexual contact mostly transmitted HIV virus. Below chart is depicted rate of transmission based on gender. Male are mostly transmitted.

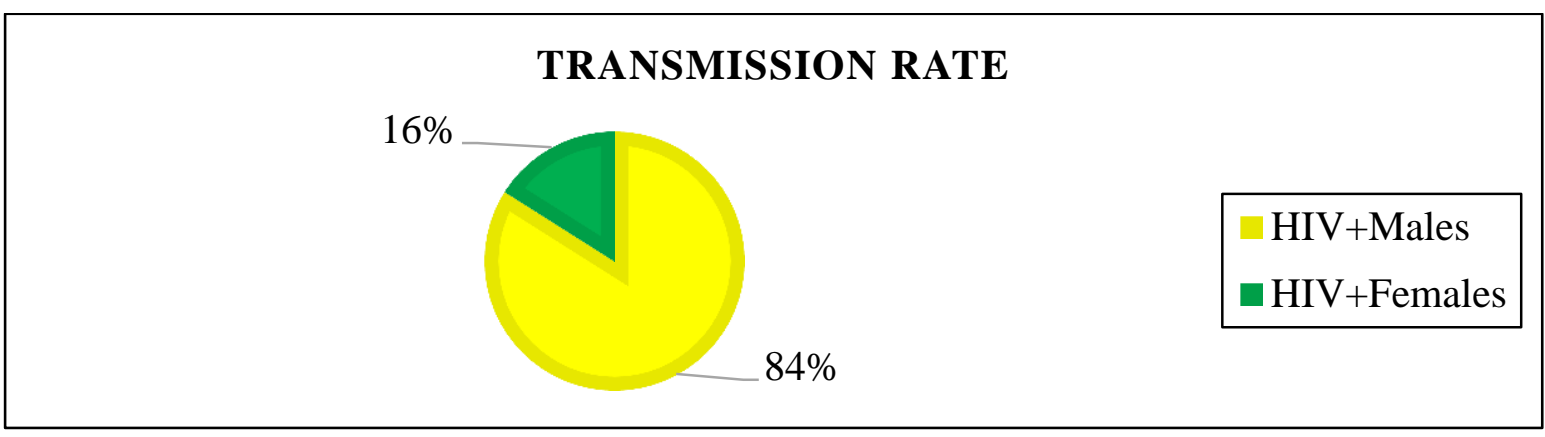

Figure 5: Transmission Rate (Source: hiv.gov). 


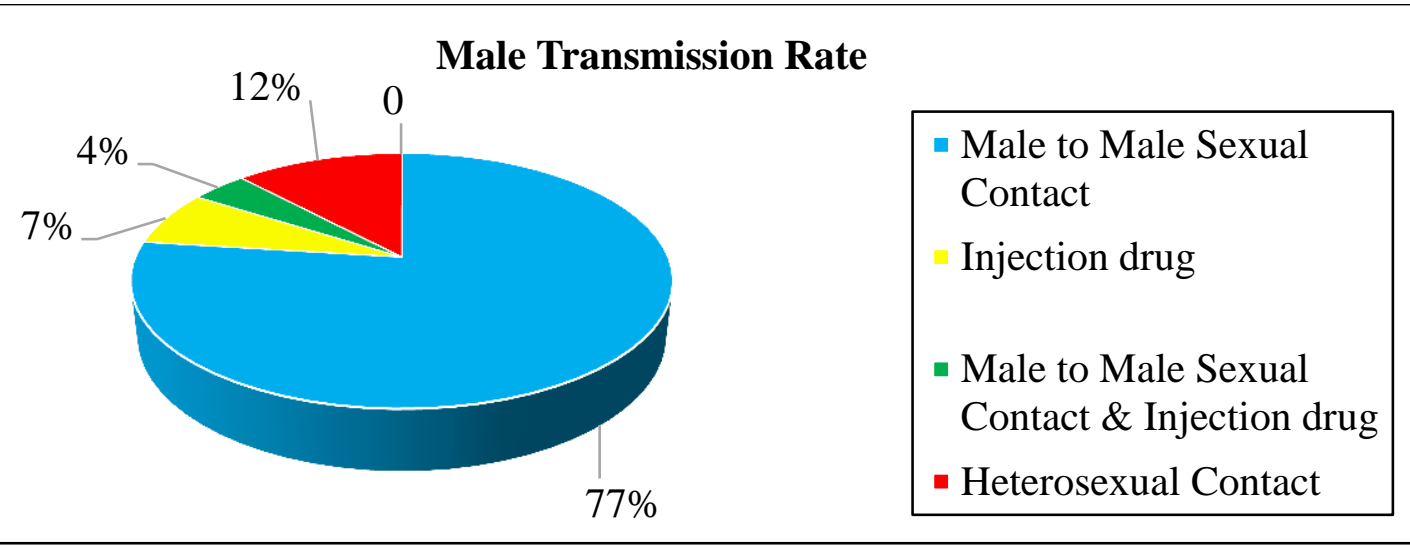

Figure 6: Male Transmission Rate (Source: hiv.gov).

Above chart is depicted male transmission via different ways. Male to male sexual contact transmission is more than $75 \%$. After that, heterosexual and injection drug are way of transmissions.

Female transmission occurs by mostly heterosexual contact and injection drug.

\section{Female Transmission Rate}

$14 \%$

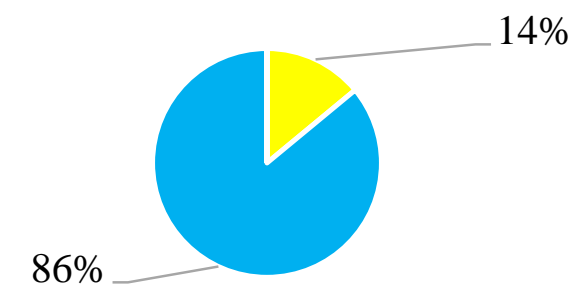

Injection drug

- Heterosexual Contact

Figure 7: Female Transmission Rate (Source: hiv.gov).

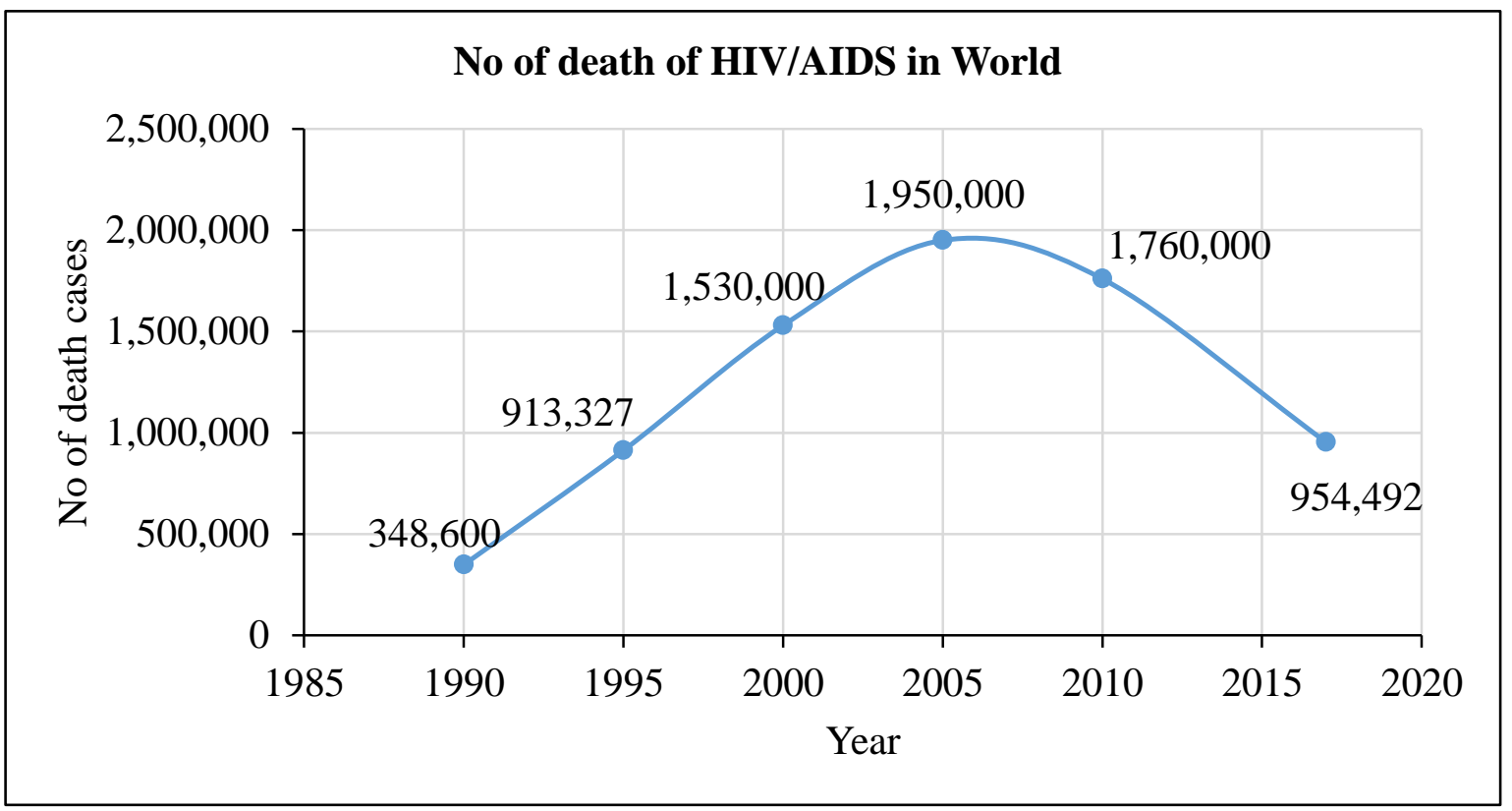

Figure 8: Deaths from HIV/AIDS, World (1990-2017) (Source: hiv.gov). 
The graph is depicted frequency of death by HIV virus from 1990 to 2017.HIV is still main life threatening disease many countries. So, overall world's death number based on all countries death number from HIV. There is a high peak on 2005 after that modern technology and ART helps to reduce number of death in 2010 onwards. Water pollution, poor sanitation and unsafe sex are reasons behind infections. People are unaware about heath related issues and not habituate about protected sex. However, now in modern era, people are conscious about these things and death cases decreased day by day.

The number of HIV-related deaths emerged throughout the 1990s and got a peak in 2005 and 2006.
During these two years, death cases were near about 2 million. However, the annual number of deaths from HIV has declined. In year of 2017, the death cases almost halved. It can be inferred from the chart the most affected age group due to AIDS. Mostly 15-49 age group are strongly infected by HIV virus. This virus is also life threatening for children and under 5 year's child. All over death rates based on all age 10.82. Death chances due to AIDS high for mid age people. Below graph is described Death rate by age in India (2017). After ART introduction, Death rates are pretty lower than 1990s.But here also, we can notice mid age people and younger people mostly infected by HIV virus. Comparing with world, death rates in India lower.

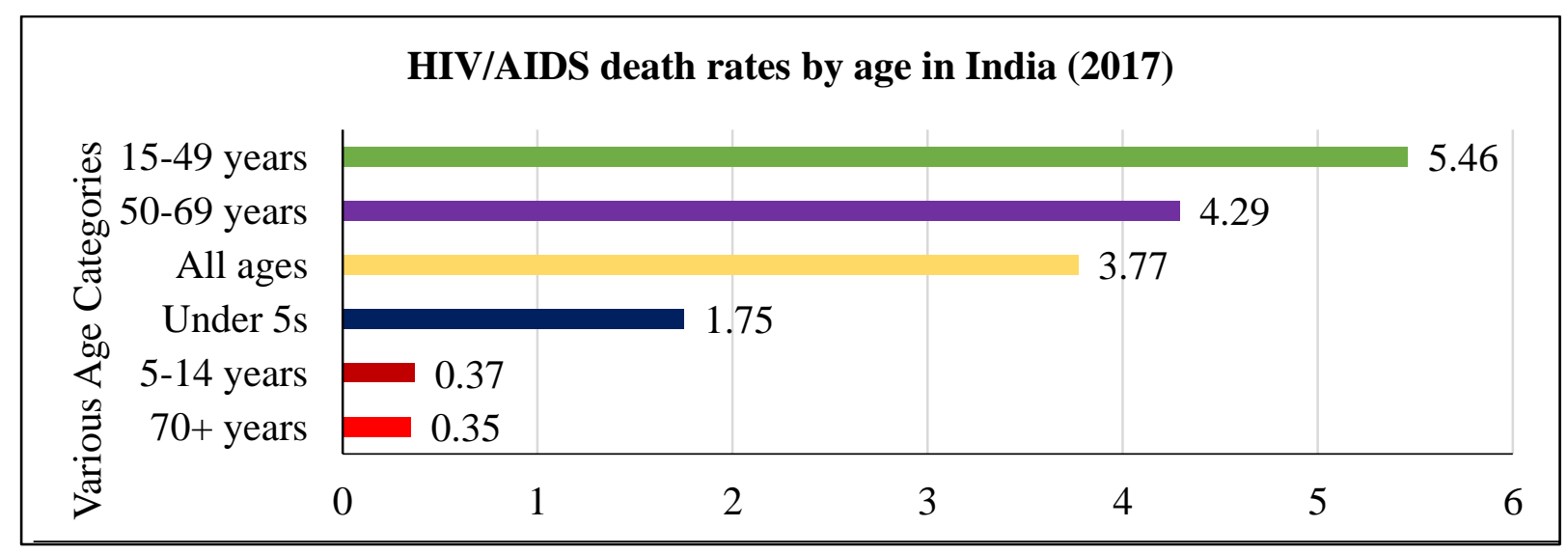

Figure 9: HIV/AIDS death rates by age in India (2017) (Source: hiv.gov).

New infection cases in the world were high in number in past. In 2000, the number of new infections accelerated. More than 3 million people newly infected in 2000. After HAART invention and pushed into HIV patient's body, death and new infections cases began decline. In 2017, number of new infections are lowest compared than 1990.

The numbers of living people with HIV were slowly increasing after HAART introduced. The increase rates of living with HIV were slowly achieved peak point.

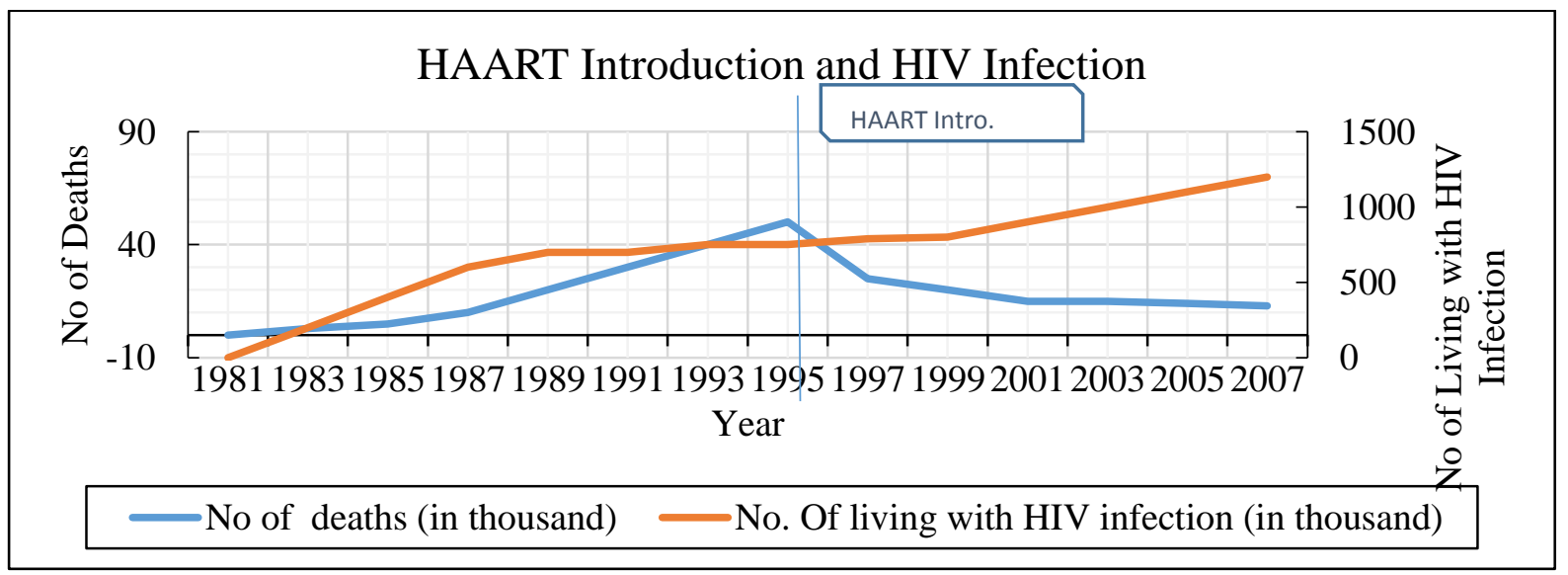

Figure 10: HAART Introduction and impacts on HIV infection (Source: hiv.gov). 
Highly active antiretroviral therapy (HAART) is the proper medications which doctors are recommended patients. Before HAART introduction death rate in world are accelerated a high pace. In 1995, HAART is introduced and after that, death rates are lower than previous year. In 2007, death rates lowest and living with HIV rates are highest.

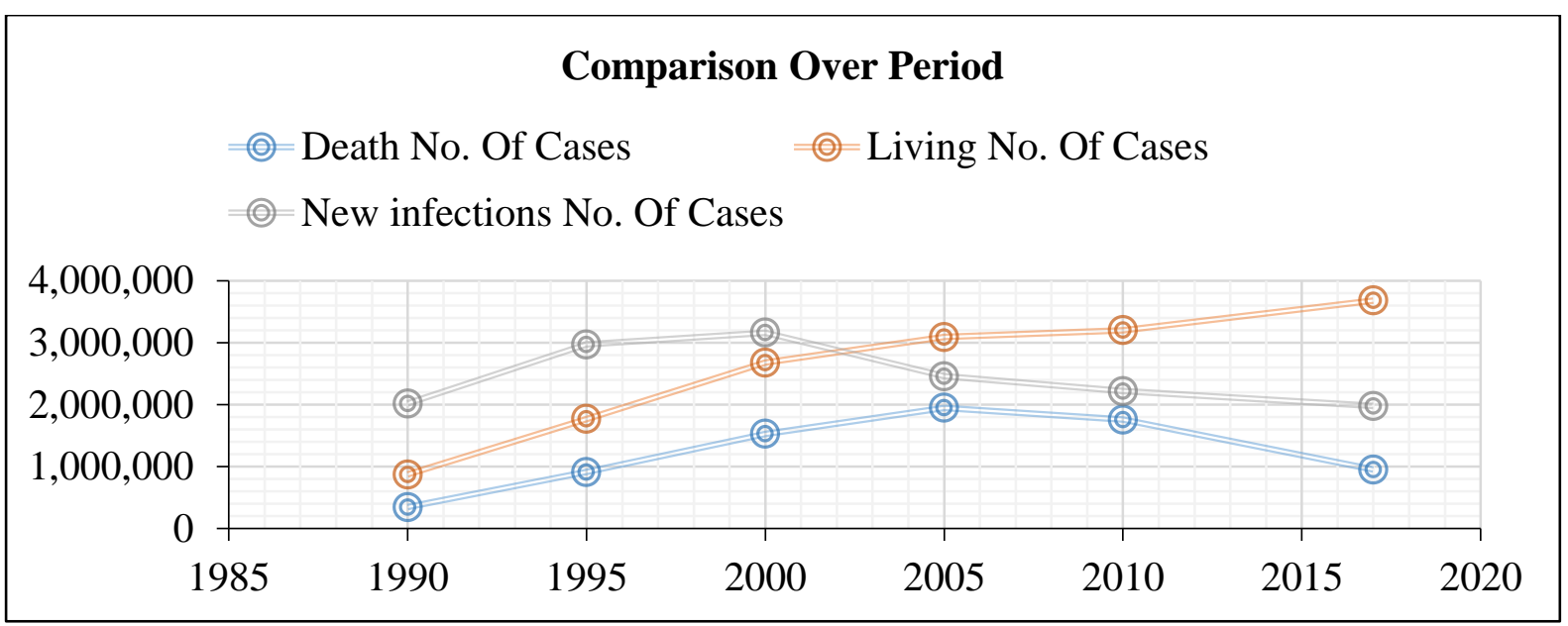

Figure 11: Comparison data of prevalence, new cases and deaths from HIV/AIDS, World (Source: hiv.gov).

Above graph is depicted the comparison among new infections, living with HIV and death cases in world. Where, the help of modern technology and ART observes it that, death rates becoming low year over year. Newly infected cases are also declining. Living with HIV cases are increasing year over year in a good pace. Doctors are hoping upcoming developments will help to increase living cases in future more.

Below graph helps to analysis HIV infections situation in UK through past two decades. New infections in UK are at declining phase, where Death rates and living with HIV rates are at stationary phase.

\section{CURRENT \& FUTURE DEVELOPMENTS}

The prospective futuristic approach in HIV diagnosis and treatment would be based on Cabenuva, the first-ever long injectable HIV treatment. It has been recently approved to be used by the FDA. Individuals living with HIV will currently choose this treatment instead of taking a pill each day whole year. The medical fraternity is eagerly awaiting a choice from the FDA on long injectable Cabenuva. Moreover, thorough research \& breakthrough are inching nearer to twice-yearly injectable for the treatment-resistant patients. In the future, the genetic mutation would be introduced during easier methods through the CRISPR-Cas9 gene-editing tool.

\section{CONCLUSION}

Treatment is main key to change the stage of HIV infections. Precaution also will help to control AIDS. People should aware about protected sexual contact. HIV is only transmitted via blood, fluids, semen and vaginal fluids. There are many myths about HIV. Therefore, people should collect only data, which are available in correct websites and authentic news portal.

\section{ACKNOWLEDGMENT}

The author wishes to acknowledge the constant support \& motivation of Fr. Dr. John Felix Raj, ViceChancellor of St Xavier's University, Kolkata. Dr. Islam also wishes to thank Dr. Manodip Ray Chaudhuri, Dean Xavier Business School for guiding \& providing valuable insights towards academic enrichment.

\section{CONFLICT OF INTEREST}

There is no conflict of interest in this present research paper. This research work is not a part of any other studies and it is our original work. Moreover, the included figures are cited with proper source and do not require any permission from the original author/publisher for use or to reproduce. 


\section{REFERENCES}

1. Barriers to HIV medication adherence: Examining distinct anxiety and depression symptoms among women living with HIV who experienced childhood sexual abuse. [Dec;2015 ];Willie TC, Overstreet NM, Sullivan TP, $\begin{array}{lll}\text { Sikkema } & \text { KJ, Hansen } & \text { NB. Behav }\end{array}$ Med. 2016 42:120-127. [PMC free article] [PubMed] [Google Scholar]

2. Borducchi EN, et al. Nature. 2020; 540: 284287.

3. Concurrent sexual partnerships and primary HIV infection: A critical interaction. Eaton JW, Hallett TB, Garnett GP. AIDS Behav. 2011;15:687-692. [PMC free article] [PubMed] [Google Scholar]

4. HIV-2: The forgotten AIDS virus. de Silva TI, Cotten M, Rowland-Jones SL. Trends Microbiol. 2008;16:588-595. [PubMed] [Google Scholar]

5. clinicaltrials.gov/ct2/show/NCT04561258

6. Internalized stigma, discrimination, and depression among men and women living with HIV/AIDS in Cape Town, South Africa. Simbayi LC, Kalichman S, Strebel A, Cloete A, Henda N, Mqeketo A.Soc Sci Med. 2007;64:18231831. [PMC free article] [PubMed] [Google Scholar]
7. nih.gov/news-events/news-releases/nihstatement-world-aids-day-2020

8. Rodger AJ et al (2019) Risk of HIV transmission through condomless sex in serodifferent gay couples with the HIV-positive partner taking suppressive antiretroviral therapy (PARTNER): final results of a multicenter, prospective, observational study. The Lancet; 393: 10189, 2428-2438.

9. Serological evidence for virus related to simian T-lymphotropic retrovirus III in residents of west Africa. Barin F, M'Boup S, Denis F, Kanki P, Allan JS, Lee TH, Essex M. Lancet. 1985;2:13871389. [PubMed] [Google Scholar]

10. WHO: Antiretroviral therapy. [Dec;2015];http://www.who.int/topics/antire troviral_therapy/en/ 2015 December [Google Scholar]

11. WHO (2018) Number of Deaths Due to HIV/AIDS. WHO. 